\title{
ACTAS DEL VI SEMINARIO SOBRE RELACIONES JURÍDICAS INTERNACIONALES: NUEVOS RETOS PARA LA ACOGIDA E INTEGRACIÓN DE LAS FAMILIAS MIGRANTES
}

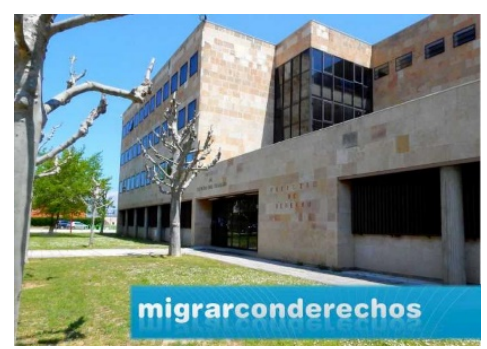

AURELIA ÁLVAREZ RODRÍGUEZ

Profesora TU, acreditada Catedrática, de Derecho Intermacional Privado

Universidad de León

\section{SEIS AÑOS DE SEMINARIOS SOBRE RELACIONES JURÍDICAS INTERNACIONALES}

El día 19 se octubre de 2018 se celebró el VI Seminario sobre relaciones jurídicas internacionales: nuevos retos para la acogida e integración de las familias migrantes, impartido en la Facultad de Derecho de la Universidad de León. Con este Encuentro, se da continuidad a los cinco seminarios anteriores, se han analizado temas de intenso calado social y repercusión jurídica relativos al derecho a vivir en familia de los migrantes y refugiados. En esta ocasión se abordaron las cuestiones relativas a la celebración del matrimonio, los matrimonios poligámicos, diálogo intercultural, sustracción de menores, expulsiones forzadas, trata de seres humanos, integración de inmigrantes, entre otros, siempre a cargo de profesionales de reconocido prestigio.

Se cumplen seis años de su andadura, que fue iniciada con el I Seminario sobre Relaciones Jurídicas Internacionales: Familia e Interculturalidad, en el que participaron profesores de otras ocho universidades, cuatro españolas (Carlos III de Madrid, León, Salamanca y Valladolid), y otras cuatro extranjeras: Université Abdelmalek Essaadi (Marruecos), Universidad Autónoma de México, Università della Calabria (Italia) y Universidad de Cartagena (Colombia); del II Seminario sobre relaciones jurídicas internacionales: Inmigración Educación e Interculturalidad, III Seminario sobre relaciones jurídicas internacionales: El reto de la integración de los inmigrantes y su repercusión en la UE; del IV Seminario sobre relaciones jurídicas 
internacionales: Avances y retrocesos en la política migratoria de la Unión Europea y del V. Seminario sobre relaciones jurídicas internacionales: infancia, MENAS, resolución de conflictos familiares y culturales.

Todos ellos han sido dirigidos por Dra. Aurelia Álvarez Rodríguez, Profesora Titular, acreditada Catedrática, de Derecho internacional privado e investigadora principal y responsable de INNAIN. Grupo de investigación relativo a la regulación de los flujos migratorios y del Grupo de Innovación docente de la ULE: "inmigración, nacionalidad e interculturalidad" (GID-INI) en colaboración con el Excelentísimo Ayuntamiento de León para llevar a cabo el Proyecto: INMIGRA\&LEÓN: CIUDAD INCLUSIVA y el CEMAI centro integral de inmigración con el patrocinio de la Junta de Castilla y León y la Universidad de León.

El presente Seminario centra sus esfuerzos en proporcionar una panorámica del régimen jurídico y status familiar de los migrantes y refugiados en el ordenamiento jurídico español, con el propósito de brindar a la sociedad una visión general desde una perspectiva multidisciplinar de carácter teórico-práctica con una amplia y variada participación de profesionales de reconocido prestigio. La jornada de trabajo ha contado con cuatro ponencias magistrales, tres mesas redondas y un taller; un total de 22 Ponentes y 5 Moderadores.

\section{ACTAS DEL VI SEMINARIO SOBRE RELACIONES JURÍDICAS INTERNACIONALES: INFANCIA, MENAS, RESOLUCIÓN DE CONFLICTOS FAMILIARES Y CULTURALES}

Este encuentro se inició con unas palabras por parte de la Dra. $\mathrm{M}^{\mathrm{a}}$ Dolores AlonsoCortés Fradejas (Vicerrectora de Relaciones Institucionales y con la Sociedad. ULE) y de Dña. Aurora Baza Rodríguez (Concejala de Familia y Servicios Sociales. Ayuntamiento de León), quienes confluyeron en el necesario fortalecimiento de los lazos de cooperación entre el Ayuntamiento y Universidad, y en la creación de espacios como el presente.

A las mismas, se unieron las felicitaciones por la iniciativa por parte de Decano de la Facultad de Derecho, Dr. D. Juan José Fernández Domínguez y de la Decana de la Facultad de Ciencias del Trabajo, Dra. Dña. Ma . De los Reyes Martínez Barroso.

Tras una descripción de las diversas actividades del Seminario, a cargo de la Directora del Seminario, Dra. Dña. Aurelia Álvarez Rodríguez, se dio comienzo a un intenso día de trabajo.

Título Ponencia Magistral: "MATRIMONIO E INMIGRACIÓN"

Ponente: Dña. Susana Salvador Gutiérrez. Magistrada-Juez del Registro Civil de Madrid

Presenta: D. José Enrique García Presa. Magistrado-Juez. Juzgado de $1^{a}$ Instancia núm. 10 de León (Juzgado de Familia) 
La legislación registral actual, que data del año 1957, pues la nueva Ley de Registro Civil, la Ley 20/2011, se prevé, que entrara en vigor, el 30 de junio de 2020, se basa en dos principios de competencia, principio nacional y el principio territorial. Por ello, todo hecho, relativo a las personas físicas, que acaece en España se inscribe en el registro civil español. A modo de ejemplo, si dos marroquís tienen un hijo se inscribirá en el registro civil español, lo mismo ocurre si éstos se casarán o uno de ellos muere.

Las resoluciones de la Dirección de los Registros y del Notariado -en adelante DGRN- han sido más restrictivas en los últimos años, debido al incremento del número de inmigrantes que residen en nuestro país.

Han aumentado el número de nacimientos de hijos de progenitores re extranjeros de matrimonios en los que al menos uno de los contrayentes no posee la nacionalidad española. Debe temerse presente, que extranjero puede acceder al registro civil a tramitar el expediente de matrimonio o a inscribir el nacimiento de su hijo sin tener residencia legal en España, pues el criterio para que el encargado del Registro Civil se declare competente se basa en el domicilio.

El domicilio en España, que determina la competencia del registro civil, se acredita con el empadronamiento del extranjero, tanto para tramitar expedientes matrimoniales o para acceder a la nacionalidad española. Si no se puede acreditar el domicilio en España el registro civil no será competente.

Una de las primeras cuestiones que plantea el nacimiento de un extranjero en España, es la inscripción de su nombre y apellidos. Estos se determinan de acuerdo a su ley personal. El ordenamiento de su nacionalidad es el que debe ser aplicado; ahora bien, en el caso de que el extranjero obtenga la nacionalidad española, su ley personal será la española, y debe ser nuestro ordenamiento el que indique el régimen de nombre y apellidos. A modo de ejemplo, los marroquíes solo tienen un apellido, al pasar a ser españoles se les duplicará éste, por razón de orden público.

Por otra parte, se debe tener en cuenta que el mero hecho de nacer en España no supone que se atribuya o imponga la nacionalidad española. El ius soli no tiene carácter general en nuestro Ordenamiento, pues éste solo opera en los supuestos previstos en el artículo 17.1. b), c) y d) del Código Civil.

Los extranjeros también acudían al Registro Civil para la solicitud de nacionalidad por el procedimiento de naturalización por residencia. Ahora bien, desde la entrada en vigor del RD 1004/2005, a partir de noviembre de 2015, el Encargado del Registro Civil del domicilio ha dejado de tramitar este expediente, ya que éste ha pasado a ser realizado mediante un procedimiento electrónico.

La mayoría de los extranjeros que han adquirido la nacionalidad española, al convertirse en españoles sus hijos, los nacidos con posterioridad a la obtención de dicha nacionalidad, son españoles de origen; en cambio, los hijos nacidos con anterioridad pueden solicitar la nacionalidad mediante el procedimiento de opción previsto en el art. 20.1.a) del Código Civil. 
Los matrimonios de complacencia o también denominados matrimonios blancos son aquellos en lo que un extranjero de un tercer país no comunitario en situación irregular contrae matrimonio con un nacional de un Estado Miembro de la UE, con la finalidad de eludir el régimen general de extranjería, y también para verse beneficiado a la hora de solicitar la nacionalidad española. El periodo para adquirir la nacionalidad española por residencia es de 10 años, con residencia legal y si se casa con un nacional del estado miembro se reduce a un año. Declarar la nulidad de un matrimonio inscrito en el registro civil solo se puede realizar mediante resolución civil.

Esquema seguido para impartir la ponencia fue el siguiente: I. Normativa registral vigente. II. Competencia del registro civil español en relación con los hechos del estado civil de los extranjeros: Principio de competencia territorial del Registro Civil. Artículos 15 y 16 Ley Registro Civil: se inscriben en el Registro Civil los hechos relativos al estado civil "acaecidos en territorio español": Régimen legal del extranjero en España; Domicilio en España. Competencia de un determinado órgano registral: expediente matrimonial y expediente DVSP. 3. Identificación del extranjero. III. Nacimientos de extranjeros en España. 1. Régimen legal de imposición de nombre y apellidos; 2. Nacionalidad española de origen del menor nacido en España de progenitores extranjeros. Artículo 17.1 c) CC. 3. Régimen legal del nombre y apellidos del nacionalizado español. IV. Nacionalidad por residencia. V. Matrimonio e inmigración: 1. Reformas en la regulación del matrimonio; 2. Requisitos de validez del matrimonio cualquiera que sea la forma de celebración. 3. Formas de celebración del matrimonio en España: A. Matrimonios en forma religiosa: a. Matrimonio en forma canónica. b. Matrimonios religiosos en formas evangélica, hebraica o islámica. c. Matrimonios religiosos que hayan obtenido el reconocimiento de notorio arraigo en España. Artículo 60.2 CC reformado por Ley 15/2015, vigente desde el 23 julio 2015. Se puede contraer matrimonio protestante (en 1984 se reconoció al protestantismo); Iglesia de Jesucristo de los Santos de los Últimos Días (2003), Testigos Cristianos de Jehová (2006), Federación de Entidades Budistas de España (2007) y, finalmente, a la Iglesia Ortodoxa en 2010. B. Matrimonio civil. 4. Control registral previo a la celebración. Expediente registral de autorización de la celebración del matrimonio civil, o en las formas religiosas judía, evangélica y notorio arraigo. 5. Control registral de la inscripción en el Registro Civil del matrimonio ya celebrado. 6. Problemática de los matrimonios blancos o de complacencia. 7. Inscripción registral del matrimonio de español con extranjero celebrado en el extranjero. 8. Vía judicial. Nulidad del matrimonio.

Título Ponencia Magistral: "NOVEDADES Y PUESTA AL DÍA EN SUSTRACCIÓN INTERNACIONAL DE MENORES"

Ponente: Dr. Francisco Javier Forcada Miranda. Letrado Jefe del Servicio de Relaciones Internacionales del CGPJ y Representante de España en la Red Internacional de Jueces de la Conferencia de La Haya

Presenta: D. José Enrique García Presa. Magistrado-Juez. Juzgado de $1^{a}$ Instancia núm. 10 de León (Juzgado de Familia) 
Cada cierto tiempo y siempre de forma recurrente, casos de sustracción internacional de menores son objeto de una intensa y emocional atención mediática. Surge, entonces, la necesidad de explicar, profundizar y clarificar una temática que presenta facetas muy diversas y una complejidad jurídica que no siempre se ha querido abordar de forma objetiva.

En España, una reforma legal de 2015 introdujo en la LEC los arts. 778 quáter, 778 quinquies y 778 sexies que, desde entonces, han venido regulando las medidas relativas a la restitución o retorno de menores en los supuestos de sustracción internacional. Su puesta en práctica se ha demostrado muy eficaz, por ejemplo, en aspectos de celeridad (seis semanas de resolución para dos instancias), que choca con conflictivos proyectos actualmente en marcha por referencia a la reforma de Bruselas II bis donde ya en junio de 2016 se abogaba inicialmente por la Comisión Europea por la existencia de tres periodos sucesivos de seis semanas para llegar a una resolución no siempre final.

La eliminación de la casación se ha configurado también como una medida de utilidad (AATS 23.11.2016, 24.05.2017 y 18.05.2018), y la vía del amparo, ajena a la regulación de la LEC, solo tuvo admisibilidad en un caso conocido que no ha sido objeto de ulterior repetición (ATC 119/2015 y STC 16/2016).

La concentración de la competencia para conocer de este tipo de casos se ajustó en su momento a estándares y recomendaciones internacionales, de forma prudente pero osada, sin que la normativa vigente haya impedido que, en casos involucrando violencia de género, se haya pretendido y se siga pretendiendo dar competencia para conocer de estos casos a juzgados de violencia de género, sin amparo adecuado en la normativa legal vigente.

Antes de la reforma de 2015 se conoció el caso resuelto por AAP Madrid 31/03/2015, y tras la reforma de 2015 cierto sector doctrinal sigue insistiendo en una idea que me parece inapropiada (vid. Cuadernos de Derecho Transnacional Vol. 10 núm. 2 pp. 615-641, octubre 2018).

Además, aspectos esenciales de todo proceso de sustracción internacional de menores, caso de la audiencia de menores y la conceptuación de la residencia habitual, gozan cada año que pasa de inusitada actualidad por increíble que pueda parecer. En el primer aspecto, frente a la dicotomía de la STJUE 22.12.2010 Aguirre Zarraga C491/10 PPU (no obligatoria la personal y directa ante el juez) frente a la STEDH 11.10.2016, Iglesias c. España (n $\left.n^{\circ} 23298 / 12\right)$, nos encontramos con que en el reciente marco legal español, la prueba pericial parece haber alcanzado casi carácter obligatorio cuando se trata de la adopción de una decisión judicial que sea relevante y afecte a los niños, ya que en estas decisiones se ha de contar con el informe colegiado de un grupo técnico y multidisciplinar especializado en los ámbitos adecuados (art. 2.5.b LO. 1/96 tras LO. 8/2015), sin olvidar la posibilidad de recabar dictamen en el art. 92.9 CC. La operatividad de esta previsión no deja de suscitar dudas y dificultades. 
En el segundo aspecto, la residencia habitual aparece dotada ahora de conceptuaciones fácticas, jurídicas e híbridas, nada pacíficas en la jurisprudencia del Tribunal de Luxemburgo.

En punto a otras novedades, y junto al creciente número de prejudiciales resueltas ya por el TJUE respecto del Reglamento 2201/2003, encontramos la reforma de Bruselas II bis iniciada en junio de 2016 y actualmente en manos de la Presidencia Austriaca, los trabajos del denominado «Working group on article 13(1)(b) of the HC 1980» que celebró su sexta reunión en La Haya en septiembre de 2018 y la venidera Conferencia de 19 de noviembre de 2018 «Safeguarding the rights of the child in cross-border family conflicts» organizada por el Parlamento Europeo «Coordinator on children's rights, formerly known as Mediator on international parental child abduction».

Algunas referencias son obligadas también al novedoso protocolo de sustracción de menores del MJU de 2017, a los recursos del Prontuario y del Atlas Judicial Europeo y a los trabajos de la Red Internacional de Jueces de la conferencia de La Haya, particularmente en el desarrollo y establecimiento de comunicaciones judiciales directas.

Primera Mesa Redonda: "FAMILIA INTERNACIONAL: NUEVOS RETOS PARA SU INTEGRACIÓN EN LA SOCIEDAD ESPAÑOLA"

Moderador/a: Dr. David Carrizo Aguado. Profesor Ayudante Derecho Internacional Privado. ULE

Si el propósito de las Conferencias magistrales era dotar al seminario de un punto de jurídico práctico los obstáculos y dificultades extras que surgen tanto en la celebración de un matrimonio mixto así como las eventual situaciones derivadas de una crisis de pareja con respecto a sus hijos que viven en países diferentes, el fin de la primera mesa redonda responde a poner de manifiesto algunas cuestiones relacionadas con la consecuencias de los diversos modelos de familia y desde la perspectiva del derecho de extranjería las trabas derivadas de los requisitos a cumplir en la normativa de extranjería

Título: "IMPLICACIONES LABORALES DE LA MATERNIDAD SUBROGADA" Comunicante: Dra. Susana Rodríguez Escanciano. Catedrática de Derecho del Trabajo y de la Seguridad Social. Universidad de León

A la luz del ordenamiento jurídico español, la "maternidad subrogada" (entendida como aquella situación en la que una mujer lleva a cabo una gestación mediante técnicas asistidas, asumiendo la obligación de entregar, de forma onerosa o lucrativa, al nacido a otro u otros contratantes, que pueden ser personas individuales, parejas de hecho o matrimonios homosexuales o heterosexuales, quienes a su vez pueden haber aportado o no sus gametos) conlleva la nulidad del contrato suscrito.

En efecto, el art. 10.1 de la Ley 14/2006, de 26 de mayo, sobre técnicas de reproducción humana asistida, califica como nulo de pleno derecho el negocio en 
virtud del cual "se concierta la gestación (con o sin precio) a cargo de una mujer que renuncia a la filiación materna a favor de un contratante o de un tercero". Los apartados 2 y 3 de este precepto añaden que "la filiación de los hijos nacidos por gestación de sustitución será determinada por el parto", quedando "a salvo la posible acción de reclamación de la paternidad respecto del padre biológico conforme a las reglas generales". Todo ello en sintonía con el art. $1271 \mathrm{CC}$, en virtud del cual la persona humana no puede ser objeto del comercio de los hombres.

Ahora bien, aun cuando puede observarse con claridad que el art. 10 Ley 14/2006 establece con absoluta perspicuidad cómo el contrato de gestación por sustitución será nulo, adquiriendo la condición de madre quien ha dado a luz, lo cierto es que nada impide que los padres intencionales acudan a un país extranjero donde está reconocida la posibilidad de la gestación por sustitución para formalizar el contrato. Sirva como dato que es legal en varios Estados de Estados Unidos (Florida, Minnesota o California), en Rusia, Ucrania, Georgia, Kazajistán, Sudáfrica, algunos Estados de México, India, Nepal, Canadá, Israel, Grecia, Holanda, Dinamarca, Bélgica, Reino Unido, Brasil, Australia o Portugal, si bien en este último país el Tribunal Constitucional en sentencia número 225/2018, de 24 de abril ha declarado la inconstitucionalidad de la legislación sobre gestación por sustitución, entendiendo necesario salvaguardar la revocabilidad del consentimiento prestado hasta el momento de entrega del nacido.

A partir de esta posibilidad transnacional, atendiendo a la normativa del Estado de destino se declarará la relación de filiación por las autoridades respectivas a favor de los padres subrogantes, debiendo proceder después, a la inscripción en el registro civil español en tales términos, trámite admitido por la Dirección General de los Registros y del Notariado, siempre que se cumplan determinados requisitos: resolución dictada por órgano judicial competente en la que conste la filiación del menor, concurrencia de libre consentimiento, renuncia de la mujer gestante y acreditación de que no se ha producido una vulneración del interés del menor.

Surge entonces una necesidad social con entidad propia, cual es el nacimiento de un hijo, que despliega sus efectos en numerosos ámbitos: alimenticios, sucesorios y, cómo no laborales. Centrando la atención en este último campo, cabe señalar que, una vez inscrito en el registro civil español el menor nacido en el extranjero mediante la técnica de maternidad subrogada, los progenitores reunirían la acreditación documental suficiente para solicitar el percibo de la prestación por maternidad, otra cosa es que la Entidad Gestora viniera denegando dicha cobertura haciendo una interpretación literal de lo previsto en el art. 177 del Real Decreto legislativo 8/2015, de 30 de octubre, por el que se aprueba el texto refundido de la Ley General de la Seguridad Social (TRLGSS), que se refiere únicamente, como supuestos de hecho protegidos, a la "maternidad, la adopción, la guarda con fines de adopción y el acogimiento familiar, siempre que, en este último caso no tenga una duración inferior a un año".

Tal postura negativa motivó una doctrina contradictoria de suplicación, pudiendo mencionar, sin ánimo exhaustivo, entre las sentencias que han reconocido el disfrute a la citada prestación, las SSTSJ, Social, Castilla y León 5 mayo 2010 (rec. 539/2010), 
Madrid 8 octubre 2012 (rec. 1875/2012), 3 marzo 2013 (rec. 3783/2012), 23 diciembre 2014 (rec. 497/2014), 17 julio 2015 (rec. 429/2015), 12 febrero 2016 (rec. 739/2015) y 31 marzo 2016 (rec. 577/2015); Canarias/Las Palmas 27 mayo 2015 (rollo 1179/2013); Asturias 20 septiembre 2012 (rec. 1604/2012); Castilla-La Mancha 27 mayo 2015 (rec. 51465/2014) ó Cataluña 23 noviembre 2012 (rec. 6240/2011), 9 marzo 2015 (rec. 126/2015), 1 julio 2015 (rec. 2460/2015), 15 septiembre 2015 (rec. $2299 / 2015$ ) y 11 febrero 2016 (rec. 6519/2015). Por el contrario, entre las sentencias que han negado la posibilidad de recibir el citado auxilio económico, procede citar, como mero botón de muestra, las SSTSJ, Social, Madrid 7 julio 2014 (rec. 142/2014) y 5 octubre 2015 (rec. 473/2015) Andalucía 4 febrero 2015 (rec. 1317/2014) ó País Vasco 13 mayo 2014 (rec. 749/2014) y 3 mayo 2016 (rec. 651/2016).

Llegados a este punto, la tesis primigenia de la Entidad Gestora, seguida por algunos Tribunales Superiores de Justicia, ha sido corregida por la Sala de lo Social del Tribunal Supremo, que ha creado un cuerpo de doctrina unificada favorable a la cobertura protectora en interés del menor [SSTS 25 de octubre 2016 (rec. 3818/2015), 16 noviembre 2016 (rec. 3146/2014) y dos de 30 de noviembre (rec. 3183 y 3219/2015), 22 noviembre 2017 (rec. 1504/2016), 29 noviembre 2017 (rec. 1430/2016) 14 diciembre 2017 (rec. 2859/2016 y 2066/2016), 2 marzo 2018 (rec. 264/2017) y AATS, 13 marzo 2018 (rec. 2059/2016) o 22 marzo 2018 (rec. 2770/2016)]. El Alto Tribunal, frente a una interpretación meramente literal sustentada sobre la base de que la legislación vigente no contempla entre las situaciones protegidas que dan derecho a la prestación de maternidad los supuestos de gestación subrogada por estar prohibida, considera que, en aquellos casos en los que el contrato de gestación se había celebrado en un países donde se admite su legalidad y la filiación a favor de los comitentes ya había sido determinada a través de la correspondiente inscripción en el registro público, es pertinente acudir a un criterio hermenéutico finalista que le lleva a razonar sobre el sentido último que justifica estas prestaciones, que no es otro que el de permitir el cuidado y atención al menor, interés que también se encuentra presente en los supuestos de maternidad subrogada. Argumenta, así, que la suspensión de la relación laboral y el reconocimiento de la prestación por maternidad constituye un medio idóneo para preservar las especiales relaciones que median entre el padre/madre y el hijo durante el período posterior al nacimiento, por lo que esta situación ha de ser debidamente protegida en la misma forma que lo son la maternidad, la adopción y el acogimiento; con independencia de que la maternidad subrogada no figure como tal y de forma expresa en el elenco de situaciones previstas, pugnaría con la lógica más primaria que se deniegue la prestación en los supuestos de gestación por sustitución cuando se reconocería ex lege si el solicitante se hubiera limitado a adoptar o a acoger a los menores.

En la actualidad, el INSS ha adoptado unos criterios interpretativos uniformizadores a la hora de otorgar la prestación por maternidad subrogada en aquellos supuestos en los que el nacimiento ha tenido lugar en el extranjero con arreglo a la legalidad de dicho país y se ha practicado la inscripción de la filiación del hijo en el Registro Civil español (consultas núm. 26/2016, de 29 de diciembre, y 4/2017, de 30 de febrero) con el fin de aclarar el régimen jurídico aplicable. 
Título: "MATRIMONIO POLIGÁMICO: ANÁLISIS DE LA RECIENTE JURISPRUDENCIA DEL TS"

Comunicante: Dra. Pilar Maestre Casas. Profesora Titular de Derecho Internacional Privado (USAL)

Es un tema que abarca varios asuntos, en esta ponencia, se refiere principalmente a las Prestaciones de la Viudedad.

Los marroquíes o senegaleses que tienen varias esposas, las cuales ante el fallecimiento de este tiene derecho a recibir una pensión de viudedad, tendrán los mismos derechos y ambas deberán recibir dicha pensión.

Especial análisis de la STS (Sala 3 ${ }^{\text {a }}$ Sección $4^{\mathrm{a}}$ ) de 24 de enero de 2018 , que reconoce la situación de poligamia a los efectos del reparto de la pensión de viudedad a las esposas de un marroquí, y aplica el Convenio de seguridad social entre España y Marruecos. En concreto en este fallo se dictamina: "1 ${ }^{\circ}$. Que la constatación de una situación de poligamia de un súbdito marroquí no impide, por razones de orden público, el reconocimiento del derecho a una pensión de viudedad en el régimen de clases pasivas del Estado, regulado por Real Decreto Legislativo 670/1987, de 30 de abril, a favor de todas las esposas que, de acuerdo con su ley personal, estuvieran simultáneamente casadas con el causante perceptor de una pensión con cargo al Estado español. $2^{\circ}$ ) que el artículo 23 del Convenio sobre Seguridad Social entre España y Marruecos, de 8 de noviembre de 1979 , por la posición jerárquica que tiene en nuestro ordenamiento jurídico tras ser publicado en el Boletín Oficial del Estado de 13 de octubre de 1982 y por el reconocimiento que le otorga el artículo 96 de la Constitución Española, permite que por vía interpretativa se pueda ampliar o extender la condición de beneficiarias de pensión de viudedad en el régimen de clases pasivas del Estado a todas las esposas que, de acuerdo con su ley personal, estuvieran simultáneamente casadas, en una situación de poligamia, con el causante perceptor de una pensión con cargo al Estado español que tenga origen marroquí, y que fuesen beneficiarias de la pensión según la legislación marroquí. $3^{\circ}$ ) que el cálculo del importe de la pensión se efectuará partiendo de que la pensión se distribuye por partes iguales entre las viudas que hayan estado simultáneamente casadas con el mismo causante $\mathrm{y}^{\circ}$ ) que el recurso de casación debe ser estimado y, con anulación de la sentencia, apreciando la vulneración del principio de igualdad denunciada en la instancia y por no haber sido cuestionada en ningún momento por la Administración la condición de beneficiaria de la esposa reclamante según la legislación marroquí, se reconocerá a doña Maribel el derecho a la percepción de la pensión de viudedad generada por su fallecido esposo de origen marroquí, don Argimiro , con efectos económicos desde el primer día del mes siguiente a su fallecimiento, acaecido el 24 de enero de 2013, y calculándose su importe partiendo de que la pensión se distribuye por partes iguales entre las viudas que hayan estado simultáneamente casadas con el mismo causante. Así mismo, se reconocerá su derecho al cobro de los haberes dejados de percibir desde esa fecha y hasta la efectiva percepción de la pensión que se le reconoce, más los intereses legales que procedan desde la presentación de la solicitud y hasta su efectivo pago". 
Ciertamente, si alguna vez se ha concedido la pensión de viudedad, la cual es única, se repartirá entre todas las mujeres que tengan, por partes iguales o según el tiempo de convivencia. En todo caso, resaltar que nuestro ordenamiento rechaza la poligamia (Vid. STS de 14 de diciembre de 2017). Algún caso llamativo, el TSJ de Catalunya hay una viuda a la que no le quisieron inscribir el matrimonio con un senegalés, que poseía nacionalidad española porque había acreditado que no había ejercido la poligamia; en cambio a su mujer le rechazan la pensión de viudedad solo porque en su ordenamiento está reconocida la poligamia.

\section{Título: "MIGRACIÓN FAMILIAR Y ESTATUTO DE CIUDADANO DE LA UNIÓN" Comunicante: Dra. Aurelia Álvarez Rodríguez. Profesora Titular, acreditada Catedrática, de Derecho Internacional Privado (ULE)}

Los nacionales de la Unión Europea y sus familiares gozan del derecho a la libre circulación en el territorio de los otros Estados Miembros. Esta libertad fundamental se basa en el principio de no discriminación por razón de nacionalidad.

La regulación se encuentra en la Directiva 2004/38/CE del Parlamento Europeo y del Consejo, de 29 de abril de 2004, relativa al derecho de los ciudadanos de la Unión y de los miembros de sus familias a circular y residir libremente en el territorio de los Estados miembros. Este texto ha sido incorporado a nuestro ordenamiento en virtud del Real Decreto 240/2007, de 16 de febrero, sobre entrada, libre circulación y residencia en España de ciudadanos de los Estados Miembros de la Unión Europea y de otros Estados Parte en el Acuerdo sobre el Espacio Económico Europeo. Este RD es de aplicación a un 58\% de la población no es española residente legal en territorio español. En principio los nacionales de los otros 27 países de la UE pueden entrar, residir y trabajar en España casi sin limitación alguna, salvo las derivadas de razón de orden público, seguridad o salud públicas. Obviamente, si se dan estos motivos se podrá denegar la entrada o se podrá instar su salida del territorio español (Vid. STJUE 13.07.2018: expulsión de ciudadano UE por conducta que constituye amenaza real, actual y suficientemente grave).

Con respecto a los familiares se debe señalar la flexibilidad del TJUE a la hora de abordar el ámbito de aplicación personal de la Directiva 2004/38 (Vid. STJUE 05.06.2018: concepto de "cónyuge", en el Derecho de la UE sobre libertad de residencia incluye a los cónyuges del mismo sexo).

El tema preocupante en estos momentos a la hora de aplicar la normativa interna española contenida en el RD 240/2007 gira en torno a los nacionales de terceros países familiares de españoles. En los últimos tiempos las autoridades españolas están siendo muy restrictivas a la hora de otorgar la TFUE, se están exigiendo medios económicos suficientes y asistencia sanitaria cubierta (Vid. STS 06.11.2018 que reitera la línea iniciada por la STS 1295/2017, de 18 de julio, y seguida en las ulteriores: $\underline{\text { STS }}$

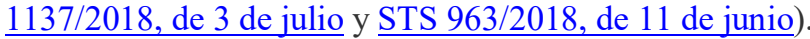


Título: "RETOS DE LA CIUDADANÍA DE LA UNIÓN: LAS (DIFÍCILES) RELACIONES ENTRE EL ESTATUTO DE CIUDADANO Y LOS DERECHOS DE RESIDENCIA"

Comunicante: Dra. Marina Vargas Gómez-Urrutia. Profesora Titular de Derecho internacional privado (UNED)

En esta comunicación, la profesora Marina Vargas Gómez-Urrutia de la Universidad Nacional de Educación a Distancia examina - a la luz de nueve asuntos resueltos por el Tribunal de Justicia (TJUE)- la cuestión siempre compleja del derecho de residencia de las nacionales de terceros países familiares de un ciudadano de la Unión en situaciones que no impliquen una previa movilidad. Es decir, la residencia de los familiares de ciudadanos sedentarios y su relación con el estatuto de ciudadano de la Unión. Como punto de partida, toma la decisión recaída en el asunto Ruiz Zambrano (C-34/09- 08/03/2011). A partir de este pronunciamiento analiza y sistematiza las sucesivas decisiones en torno a tres momentos temporales o épocas. En la primera época el hilo conductor es el presupuesto de la movilidad intraeuropea del ciudadano (libre circulación) como exigencia para el disfrute del derecho de residencia de sus familiares no europeos. ¿MOVERSE O NO MOVERSE? es la cuestión genérica; la respuesta se construye desde el Fallo en el asunto Ruiz Zambrano incluyendo dos asuntos más: el caso Shirley McCarthy (C-434/09 - 05/05/2011) y el caso Murat Dereci (C-256/11 - 15/11/2011). En la segunda época el hilo conductor es disfrute de los derechos de residencia asociados al estatuto de ciudadano. Es decir, el ámbito de aplicación de la Directiva de libre circulación (2004/38) y su relación con la ciudadanía de la Unión (arts. 20 y 21 TFUE). ¿SOY UN "VERDADERO" CIUDADANO EUROPEO? es la cuestión genérica; la respuesta se construye a la luz de cinco asuntos que presentan matices respecto de la doctrina Ruiz Zambrano. Son los casos: Iida (C-40/11 - 08/11/2012), O. y S. (C-356/11 y C-357/11 - 06/12/2012), Alopka (C- 86/12 - 10/10/2013), Rendón Marín (C-165/14 - 13/09/2016) y ChávezVilchez (C-133/15 - 10/05/2017). En la tercera época el hilo conductor es la "pérdida" de la condición de ciudadano en movimiento; es decir, cuándo “dejamos" de ser ciudadanos europeos en movimiento y nos (re) convertimos en ciudadanos sedentarios. ¿SOY UN CIUDADANO EUROPEO EN MOVIMIENTO? es la pregunta genérica; la respuesta se construye en torno al caso Tofik Lounes (C 165/16, 14/11/2017). La conclusión general de esta comunicación puede resumirse en dos ideas: (1) libre circulación de personas y estatuto de ciudadano de la Unión son dos cuestiones indisolublemente unidas cuyas relaciones no resultan fáciles en absoluto; (2) la aplicación de los derechos de la ciudadanía exige una vinculación con el Derecho de la Unión que se da siempre que la libre circulación sea efectiva (Directiva 2004/38) pero que es más difícil de activarse cuando no haya movimiento transfronterizo. En estos casos, para la invocación directa del estatuto de ciudadano de la Unión (art. 21 TFUE) ha de buscarse un vínculo lo suficientemente relevante y poderoso como para "sacar" el supuesto de la esfera meramente interna y convertirlo en un supuesto europeo. 
Título: "LA INTERPRETACIÓN DEL ART. 57.2 LOEX CONFORME A LA STS 893/2018, DE 31 DE MAYO"

Comunicante: Dra. Susana Cuadrón Ambite. Abogada del Colegio de Abogados de Madrid. Profesora colaboradora de Derecho Penal en ICADE. Tutora de Derecho Internacional Privado en Extranjería (UNED) y Migración

La interpretación del artículo 57.2 de la LOEx, ha sido objeto de polémica y de distintas interpretaciones. Tras la Sentencia del Tribunal Supremo de 31 de mayo del 2018, parece que dicha cuestión ha sido resuelta: el criterio que contempla es que ha de estarse a la pena en abstracto atribuida al delito en el Código Penal y ello porque el propio artículo 57.2, en realidad, dispone la expulsión del extranjero que cometa un delito doloso sancionado en España con la pena superior a un año. El propio Tribunal modula tal interpretación toda vez que, en nuestro Código Penal, existen delitos que son sancionados al mismo tiempo con pena privativa de libertad inferior o superior al año. En este supuesto, la expulsión solo procedería en el caso de que "la sanción de la pena privativa de libertad prevista en el Código Penal para el delito concernido, ha de ser superior a un año en todo su ámbito o espectro sancionador".

Sin embargo, tal Sentencia ha sido objeto de dos votos particulares que indican el automatismo en el que incurre el Tribunal Supremo con tal interpretación, automatismo que debe quedar excluido conforme a nuestro sistema en el sentido de que hay que valorar las circunstancias concurrentes en el supuesto infractor para determinar o no la procedencia de la expulsión.

Taller de Trabajo: "Acceso a la nacionalidad española: especial análisis del nuevo procedimiento de naturalización por residencia"

Modera: Dra. Aurelia Álvarez Rodríguez. Profesora Titular, acreditada Catedrática, de Derecho Internacional Privado (ULE)

El objetivo de este taller era brindar a los asistentes de una perspectiva práctica el nuevo procedimiento de naturalización por residencia. Todos los comunicantes describen el protagonismo que han asumido en materia de acceso a la nacionalidad española

Título: "NUEVA APLICACIÓN DEL CONSEJO GENERAL DE LA ABOGACÍA ESPAÑOLA Y NUEVO SERVICIO DEL COLEGIO DE ABOGADOS DE LEÓN" Comunicante: D. Fernando Rodríguez Santocildes. Decano del llustre Colegio de Abogados de León

El día 25 de julio de 2017 el Ministerio de Justicia y el Consejo General de la Abogacía Española suscribieron un Convenio de habilitación para la presentación electrónica de los Expedientes de Nacionalidad por residencia.

La Ley 19/2015, de 13 de julio, de medidas de reforma administrativa en el ámbito de la Administración de Justicia y del Registro Civil, en su Disposición Final Séptima, y con objeto de agilizar la tramitación de los expedientes de nacionalidad, se establece 
un nuevo procedimiento para la obtención de la nacionalidad española por residencia, que tendrá carácter electrónico y su instrucción corresponderá a la Dirección General de los Registros y el Notariado. Dispone que todas las comunicaciones relativas a este procedimiento se efectuarán electrónicamente.

Desde la suscripción del citado Convenio el CGAE ha creado una aplicación a través de la cual los Colegios de Abogados van a poder ofrecer a sus abogados a través de la plataforma de servicios electrónicos RedAbogacía- la posibilidad de tramitar de los "expedientes de nacionalidad por residencia" de sus clientes. y la remisión de los expedientes a la Dirección General de los Registros y del Notariado a través de la infraestructura tecnológica del Ministerio de Justicia.

El Colegio pone a disposición de sus colegiados un nuevo servicio que facilita su labor profesional agilizando la tramitación de los expedientes tanto para los abogados como para sus clientes, reduciendo el tiempo de respuesta de la resolución del expediente.

La aplicación no es de uso obligado ni para el Colegio ni para el Colegiado. Es el Colegio el que decide si quiere ofrecer este nuevo servicio a sus Colegiados. Para ello tendrá que solicitar el alta en el mismo, remitiendo la adhesión al convenio suscrito con el Ministerio de Justicia.

El abogado que desee utilizar el servicio tendrá que adherirse al convenio. Para facilitar este trámite y que no suponga una carga administrativa para el colegio, se ha habilitado una funcionalidad dentro de la aplicación para realizar este trámite.

La principal función del Colegio consiste en revisar la conformidad de la documentación presentada por el abogado y extender el "Certificado de Revisión Colegial (CRC)", que acompañe a cada solicitud, indicativo de que concurren todos los requisitos exigidos para la obtención de la adquisición de la nacionalidad por residencia y, en particular, los establecidos en el artículo $5^{\circ}$ del Real Decreto $\underline{1004 / 2015}$. Se generará de forma automática por la aplicación cuando el expediente está completo, pulsando el botón de "Enviar al Ministerio de Justicia".

La presentación de la documentación por las vías y a través de los procedimientos previstos por la Dirección General de los Registros y del Notariado. Se realiza pulsando el botón de "Enviar al Ministerio de Justicia" y el expediente se trasmite de manera electrónica.

Igualmente asegura el pago de la tasa correspondiente en relación con la tramitación del expediente. Se realiza verificando desde la pestaña "Tasas" del expediente la existencia del resguardo de haber realizado el pago correspondiente.

Título: "APRENDIZAJE DEL ESPAÑOL PARA EXTRANJEROS"

Comunicante: Dr. Mario de la Fuente García. Director de la Fundación Sierra Pambley 
Si un inmigrante quiere conseguir la nacionalidad, tiene que pasar dos exámenes: uno de cultura y conocimientos socioculturales y otro de idioma. Explicaré brevemente cómo son estas pruebas para que podamos entender a qué se enfrentan estas personas.

El CCSE es un examen tipo test en el que hay 25 preguntas sobre 2 grandes áreas temáticas:

1. "Gobierno, legislación y participación ciudadana en España $(60 \%$ de las preguntas)".

2. "Cultura, historia y sociedad españolas (40 \% de las preguntas)".

En general, suele ser un examen que los inmigrantes aprueban con relativa facilidad si lo preparan bien. Sin embargo, desde nuestro punto de vista hay varios aspectos claramente mejorables en este proceso:

En primer lugar, la inscripción y el pago de los derechos de examen solo se pueden hacer a través de internet. El estudiante necesita un correo electrónico, una tarjeta de crédito preparada para el comercio electrónico (no todas lo están) y $85 €$. Pero lo más importante es que necesita tener ciertos conocimientos informáticos para realizar todo este proceso. Algunos inmigrantes tienen estas habilidades pero no se puede afirmar que todos sean capaces de hacerlo.

En segundo término, el estudiante no dispone de materiales didácticos de calidad para preparar este examen. Todo lo que el Instituto Cervantes (el organismo encargado de estos exámenes) les da es un documento de 93 páginas con todas las preguntas y sus correspondientes respuestas, además hay una serie de textos sobre cada tema que el estudiante debe aprender para aprobar el examen. Pero estos textos no han sido elaborados desde una perspectiva pedagógica ni didáctica y, en ocasiones, contienen estructuras gramaticales y vocabulario demasiado complicados para el nivel de idioma que se les exige.

En el examen de idioma, por otra parte, los estudiantes tienen que demostrar un determinado nivel en lo que en enseñanza de idiomas se conoce como las cuatro destrezas: hablar, escuchar, leer y escribir. El nivel que tienen que demostrar es A2, un nivel inicial de español pero suficiente para comunicarse en nuestro país.

Quizá el principal problema que afecta a la enseñanza de español a inmigrantes es la alarmante falta de profesionalización de este sector. En nuestra sociedad actual existe, por desgracia, la percepción de que enseñar español a inmigrantes es algo que tiene que ver más con la atención social que con la ciencia lingüística y de que, en consecuencia, una persona que se dedique a esta labor no necesita poseer unos sólidos conocimientos gramaticales ni estar al tanto de los últimos avances en la disciplina. Este hecho determina que en numerosas organizaciones se deje esta labor en manos de voluntarios con la misma cantidad de buenas intenciones que de desconocimiento del funcionamiento gramatical del español y de las herramientas didácticas más básicas. 
Me gustaría terminar con la pequeña historia de Larbi, uno de nuestros alumnos en Sierra Pambley. Cuando llegó a nuestras clases, apenas hablaba español pero después de un año hicimos un ejercicio en el que pedíamos a nuestros estudiantes que eligieran su palabra favorita del español. La palabra que escogió fue "camino", porque después de mucho trabajo había conseguido entender los famosos versos de Machado y le habían encantado. Para mí, esta anécdota muestra que si trabajamos con seriedad y profesionalidad en la enseñanza de español a inmigrantes, podremos ayudar a estas personas a construir su propio camino en nuestro país.

Título: "UN CASO REAL: 11 AÑOS SIENDO APÁTRIDA"

Comunicante: D. Vicente Guillan Martínez. Director de análisis y planificación en Caritas Diocesana León

Hace 11 años, nació Valladolid (España), el 15 de mayo de 2007 en el Hospital Clínico Universitario de Valladolid, tal y como consta en Registro Civil de dicha ciudad. Con posterioridad al nacimiento se solicitó su inscripción también ante las autoridades marroquíes. Sin embargo, el Consulado General del Reino de Marruecos acreditado en Madrid, con fecha 16 de marzo del 2012, denegó dicha inscripción "por encontrarse la madre casada con otro hombre que no es el padre de dicha niña".

Las autoridades españolas siendo conocedoras de los principios que rigen en el Reino de Marruecos sobre atribución de la nacionalidad iure sanguinis no han considerado a la niña como española, lo cual ha conllevado que se encuentre en una situación de apatridia legal y fáctica; pues la negativa de las autoridades marroquíes a inscribir en sus Registros el nacimiento de la menor implica que tampoco tiene la nacionalidad.

Desde la asesoría de Cáritas, con ayuda de Dra. Dña. Aurelia Álvarez Rodríguez, se alegó que España está obligada por la Convención sobre los Derechos del Niño, adoptada por la Asamblea General de las Naciones Unidas y firmada en Nueva York el 20 de noviembre de 1989. El art. 7 del mencionado texto internacional impone a los Estados, obligados por el mismo, la concesión de la nacionalidad del país de nacimiento, al disponer en su apartado 2 que "Los Estados Partes velarán por la aplicación de estos derechos de conformidad con su legislación nacional y las obligaciones que hayan contraído en virtud de los instrumentos internacionales pertinentes en esta esfera, sobre todo cuando el niño resultara de otro modo apátrida". Esta imposición también se recoge a nivel estatal en el art. 17.1.c) del Cc. Ciertamente, la afirmación de que son españoles los nacidos en España de padres marroquíes, es difícil de justificar. En principio, sólo serán españoles algunos de los hijos de marroquíes nacidos en territorio español. Esto se debe a que la ausencia de apatridia originaria de los hijos va a estar condicionada al cumplimento de algunos requisitos, como por ejemplo, que el matrimonio de los progenitores no sea reconocido por las autoridades marroquíes, al que debemos añadir a este caso.

Ciertamente, esto dificultaba el acceso a la nacionalidad española. Ahora bien, se justificó la existencia de algunos casos previos resueltos por parte del Ministerio de Justicia (Res. DGRN de 30 de abril de 1997; Res. DGRN 5ª de 15 de febrero de 1999; 
Res. DGRN $1^{\text {a }}$ de 16 de enero de 2002; Res. DGRN $4^{\text {a de }} 23$ de abril de 2002; Ress. DGRN $7^{\text {a }}$ de 10 de septiembre, $8^{\text {a }}$ de 16 de septiembre, $1^{\text {a }}$ de 13 de diciembre de 2002 y $4^{\mathrm{a}}$ de 14 de junio de 2005).

Para más información:

Álvarez Rodríguez, Aurelia y OPI.: Nacionalidad de los hijos de extranjeros nacidos en España, Madrid, 2006.

Álvarez Rodríguez, Aurelia.: “Algunos de los niños de extranjeros nacidos en España son españoles".

Título Ponencia Magistral clausura de la mañana: "EL RETO MIGRATORIO EJE CENTRAL DE LA REUNIÓN DE SALZBURGO Y LAS LÍNEAS ESENCIALES DE LA ACTUAL POLÍTICA ESPAÑOLA SOBRE MIGRACIONES: CIUDADANÍA ESPAÑOLA EN EL EXTERIOR E INMIGRANTES EN ESPAÑA"

Ponente: D. José Alarcón Hernández. Director General de Migraciones

La globalización conlleva incremento de traslados, movimientos y desplazamientos de personas, las migraciones han aumentado en los últimos anos. El número de migrantes en el mundo, de acuerdo con los últimos informes de la OIM han alcanzado los 258 millones de inmigrante. En nuestro país, actualmente residen de forma legal 5 millones de extranjeros, de los cuales 3 millones son comunitarios y 2 millones extracomunitarios. También hay que señalar que más de 2 millones de españoles se encuentran viviendo fuera de España. Los jóvenes españoles, ante la ausencia de oportunidades se trasladan fuera de nuestro país para poder acceder a un puesto de trabajo. Con ello, se puede afirmar que la inmigración y la emigración son factores que marcan el devenir de la sociedad española.

Los países europeos están haciendo unos discursos y unos análisis excesivamente pegados a una visión política que no está tratando el fenómeno tal cual es.

A partir del año 2015 se ha producido una entrada masiva de inmigrantes debido a la guerra de Siria. Debido a esto muchos países europeos han sufrido un impacto mental, esto ha tenido repercusión en los parlamentos y en la sociedad, lo cual está perjudicando al fenómeno de la inmigración.

Nuestra alternativa es hacer una política adaptada a nuestros tiempos, una política que luche contra la inmigración irregular. Aunque ahora no necesitamos mano de obra extranjera es posible que en un futuro no muy lejano si sea necesario.

La inmigración no es positiva ni negativa sino necesaria, y es necesario establecer vías de entrada regulares y seguras, que los inmigrantes accedan al territorio español, que es territorio Schengen, con un contrato de trabajo y/o itinerario de adaptación.

La política de integración en el Gobierno hasta 2014 ha sido un referente y tiene que volver a serlo. 
Los días 19 y 20 de septiembre de 2018, en Salzburgo, los Ministros de Justicia e Interior se reunieron para examinar una vez más la agenda en materia migratoria. En las sesiones de trabajo se puso de manifiesto que algunos países de la UE están manteniendo discursos y análisis excesivamente pegados a una visión política que no es tal cual es, pues hacen utilitarismo del fenómeno.

A partir del año 2015 se ha producido una entrada importante de personas que huyen de conflictos bélicos, sobre en el caso de los nacionales procedentes de Siria. Este éxodo ha sido retransmitido de un modo directo por los medios de comunicación. Y, los discursos de rechazo han tenido una repercusión en los parlamentos y en la sociedad, excesivo y poco positivo en cuanto al fenómeno de inmigración en el conjunto.

Son percepciones alejadas de la realidad. Ciertamente, la lucha contra la inmigración irregular, es un eje de la política migratoria. Sin embargo, hay un error de diagnóstico, lo que puede generar rechazo en la población. Es materialmente imposible que un país expulse a tantos ciudadanos que han llegado irregularmente a Alemania o como Suecia o Finlandia y no han conseguido el estatuto de asilado. Debemos preocuparnos y contrarrestar otro tipo de modelo, la alternativa es una política adaptada al tiempo. En este año no estamos necesitando mano de obra extranjera, pero se prevé que en futuros años si lo sea. La inmigración no es positiva ni negativa, es necesaria, y es necesario tener vías de entrada regular y segura para poder tener un contrato de trabajo, o itinerario de adaptación.

La política de integración en el gobierno ha sido un referente y tiene que volver a ser un referente. El gobierno anterior, se puso un 0 en política migratoria.

PD. Las labores que desempeña la Dirección General de Migraciones están delimitadas en el art. 4 del Real Decreto 903/2018, de 20 de julio, por el que se desarrolla la estructura orgánica del Ministerio de Trabajo, Migraciones y Seguridad Social. Este precepto establece que: "1. Corresponden a la Dirección General de Migraciones las funciones siguientes: a) La elaboración de proyectos normativos y la realización de informes sobre materias relacionadas con la inmigración y la emigración, así como la preparación de propuestas normativas relacionadas con la elaboración, aprobación, transposición y aplicación de normas de la Unión Europea o de ámbito internacional, en materias de su competencia. b) La elaboración de instrucciones de desarrollo normativo en el ámbito de la Dirección General dirigidas a los órganos periféricos de la Administración General del Estado. c) El apoyo técnico de la participación en el ámbito de la Unión Europea y de otras organizaciones internacionales en materia de migraciones, sin perjuicio de lo previsto en el artículo 2.3; así como la coordinación, como punto de contacto nacional, de la Red Europea de Migración en España. d) La ordenación y gestión de los procedimientos de concesión de autorizaciones previstas en la normativa general sobre extranjería e inmigración u otra normativa cuya resolución corresponda a la Dirección General de Migraciones. e) La coordinación funcional con otros centros directivos y con las oficinas de extranjería, así como el apoyo a los órganos periféricos de la Administración General del Estado, y el seguimiento de su actuación en procedimientos de autorizaciones de trabajo y residencia, o en materias de 
inmigración de su competencia. f) La propuesta justificada de necesidades de medios e infraestructuras para la gestión de procedimientos de inmigración y la coordinación para su implantación por los órganos competentes. g) La ordenación de la gestión colectiva de contrataciones en origen, los procesos de selección y contratación de trabajadores extranjeros en sus países de origen, o extranjeros documentados con visados de búsqueda de empleo, así como el apoyo a los trabajadores seleccionados y seguimiento de las contrataciones. h) La atención a los españoles en el exterior y retornados. i) El reconocimiento y gestión de prestaciones económicas y ayudas asistenciales destinadas a españoles en el exterior y retornados. j) La asistencia sanitaria, en su país de residencia, a los españoles de origen beneficiarios de prestaciones económicas. $\mathrm{k}$ ) La gestión de los programas de subvenciones y ayudas destinados a los españoles en el exterior y retornados. 1) La coordinación funcional de la actuación de los órganos periféricos de la Administración General del Estado con competencias en materia de emigrantes retornados. 2. De la Dirección General de Migraciones dependen, con nivel orgánico de Subdirección General: a) La Subdirección General de Régimen Jurídico, a la que corresponde el ejercicio de las funciones enumeradas en los párrafos a), b), y c) del apartado 1. b) La Subdirección General de Inmigración, a la que le corresponde el ejercicio de las funciones enumeradas en los párrafos d), e), f) y g) del apartado 1. c) La Subdirección General de Emigración, a la que corresponde el ejercicio de las funciones enumeradas en los párrafos h), i), j), k) y l) del apartado l”.

Título Ponencia Magistral apertura de la sesión de la tarde: "PROGRAMAS Y ACCIONES DE LA ACTUAL POLÍTICA DE ACOGIDA E INTEGRACIÓN DE LAS PERSONAS NECESITADAS DE PROTECCIÓN HUMANITARIA"

Ponente: Dña. Estrella Rodríguez Pardo. Directora General de Integración y Atención Humanitaria.

Presenta: D. José Varela Rodríguez. Presidente de Cruz Roja España en Castilla y León

La protección internacional es un derecho reconocido en la declaración de derechos del hombre concretada (Derecho de asilo o protección subsidiaria).

Las personas sujetas a protección internacional tienen derecho a la no devolución, al acceso al servicio público de empleo, a la sanidad, etc.

En nuestro país el Ministerio del Interior se encarga de la instrucción y resolución de la protección y el Ministerio Trabajo, Migraciones y Seguridad Social tiene potestad para desarrollar lo que es el proceso de acogida y protección.

La reubicación es traer personas solicitantes de asilo de Italia y Grecia. Refugiados ya reconocido de terceros campos de refugiados a España, ahora mismos hay una Delegación en Jordania conjuntamente con el Ministerio del Interior para seleccionar a mil personas. 
España no era un país de asilo. Nos vamos a convertir en un país de asilo, debemos de reorientar la política de asilo y de acogida. En los últimos años se ha hecho un esfuerzo por aumentar las plazas de acogida de refugiados, de tener 1000 a tener cerca de 8000 . El sistema no da, no podemos seguir creciendo indefinidamente.

Hoy en día, tal y como está el sistema, está pensando para trabajar en itinerarios individuales de integración, es un sistema gradual, no es para todos igual. Depende mucho de las circunstancias personales se prepara su itinerario.

La fase previa, cuando manifiestan su voluntad de protección internacional, en ese momento si no hay plazas de protección internacional van a una asignación provisional de acogida, para poder alojarse. Luego se pasa a su acogida en un centro, público o concertado. La siguiente fase es la de autonomía, donde se alquila un piso y se le da unas ayudas para poder pagar el alquiler, la alimentación, si tienen hijos se les escolariza, etc. Se trata de un sistema de protección que dura de 18 a 24 meses para intentar que estas personas alcancen un sistema de autonomía suficiente como para vivir en nuestro país. Además la legislación establece que pueden trabajar a partir de los 6 meses. También se suministra asistencia jurídica, y ayuda psicológica, así como buenos traductores.

PD. Las labores que desempeña la Dirección General de Integración y Atención Humanitaria están delimitadas en el art. 5 del Real Decreto 903/2018, de 20 de julio, por el que se desarrolla la estructura orgánica del Ministerio de Trabajo, Migraciones y Seguridad Social. Este precepto establece que: "1. Corresponden a la Dirección General de Integración y Atención Humanitaria las siguientes funciones: a) La planificación, desarrollo y gestión del sistema nacional de acogida integral e integración de solicitantes de asilo, refugiados y otros beneficiarios de protección internacional, apátridas y personas acogidas al régimen de protección temporal. b) La gestión de subvenciones y la colaboración con entidades públicas y privadas cuyas actividades se relacionen con la acogida e integración de solicitantes de asilo, refugiados y otros beneficiarios de protección internacional, apátridas y personas acogidas al régimen de protección temporal. c) La planificación, desarrollo y gestión de programas de atención humanitaria a inmigrantes y de intervención urgente para situaciones de carácter excepcional, en colaboración, en su caso, con las comunidades autónomas, entidades locales, así como con entidades públicas y privadas. d) La planificación, gestión y seguimiento de los centros de estancia temporal de inmigrantes (CETI) y de los centros de acogida a refugiados (CAR). e) La gestión de subvenciones de carácter estatal en materia de integración de inmigrantes y la colaboración con entidades públicas y privadas cuyas actividades se relacionen con dicha materia. f) El desarrollo y gestión de programas vinculados al retorno de inmigrantes, la reagrupación familiar, y la acogida e integración de inmigrantes con visado de búsqueda de empleo. g) La gestión de los fondos y planes de acción de la Unión Europea en materia de asilo, migración e integración. h) La concertación con otros Departamentos ministeriales, comunidades autónomas, entidades locales y entidades públicas y privadas de actuaciones de promoción de la integración de inmigrantes, de acogida e integración de solicitantes de asilo, refugiados y otros beneficiarios de protección internacional, apátridas y personas acogidas al régimen de protección temporal. 2. De la Dirección General de Integración y Atención 
Humanitaria dependen, con nivel orgánico de Subdirección General: a) La Subdirección General de Programas de Protección Internacional, a la que corresponde el ejercicio de las funciones enumeradas en los párrafos a) y b) del apartado 1. b) La Subdirección General de Programas de Atención Humanitaria y Centros de Migraciones, a la que corresponde el ejercicio de las funciones enumeradas en los párrafos c), d), e) y f) del apartado 1. c) La Subdirección General de Integración y Relaciones Institucionales, a la que corresponde el ejercicio de las funciones enumeradas en los párrafos g) y h) del apartado1. 3. De la Dirección General de Integración y Atención Humanitaria depende, con el rango que se determine en la correspondiente relación de puestos de trabajo, el Observatorio Español del Racismo y la Xenofobia, al que corresponden las siguientes funciones: a) La recopilación y análisis de la información sobre racismo y xenofobia para el conocimiento de la situación y de sus perspectivas de evolución, a través de la puesta en marcha de una red de información. b) La promoción del principio de igualdad de trato y no discriminación y lucha contra el racismo y la xenofobia. c) La colaboración y coordinación con los distintos agentes públicos y privados, nacionales e internacionales vinculados con la prevención y lucha contra el racismo y la xenofobia".

Segunda Mesa Redonda: "ACCESO, ACOGIDA E INTEGRACIÓN DE LAS PERSONAS NECESITADAS DE PROTECCIÓN HUMANITARIA ESPECIAL ATENCIÓN A LA VÍCTIMAS DE TRATA Y VIOLENCIA DE GÉNERO EN EL ÁMBITO DE ACTUACIÓN DE LAS ONGs LEONESAS"

Moderador/a: Dr. Salvador Tarodo Soria. Profesor Titular de Derecho Eclesiástico del Estado. ULE

Título: "INFORMES DE AMNISTÍA INTERNACIONAL SOBRE LA CRISIS EN LA GESTIÓN DE LA PROTECCIÓN INTERNACIONAL DE LOS MIGRANTES FORZOSOS"

Comunicante: Dr. José Manuel Paredes Castañón. Vicepresidente de Amnistía Internacional en Castilla y León

Amnistía Internacional es una organización internacional, pero no es de ayuda directa

Es más una labor de vigilancia, supervisión y denuncia de derechos humanos.

Alrededor de 21 millones de personas refugiadas, la mayoría refugiadas en países pobres. Los que llegan a Europa son una pequeña minoría.

Tenemos desde el punto de vista de protección de derechos humanos dos problemas graves globales.

- Sistema de asilo de los años 80. No se ha mejorado, si reformado. Está colapsado. El sistema de asilo español es inadecuado e insuficiente. Fenómeno de lo que ocurre en Ceuta y Melilla, que son "ciudades sin ley", es decir, decisiones policiales sin ningún tipo de sustento. 
- Situación de las personas migrantes que llegan a España por multitud de razones, en el caso de que accedan a España y permanezcan sin el permiso de residencia, dependiendo del lugar y dependiendo de las vicisitudes de la administración pública en cada lugar, se pueden encontrar en situación de una relativa protección o completamente desasistidos.

En el año 2012 el Ordenamiento español reservaba el derecho al acceso al sistema sanitario a la situación o condición administrativa de la residencia legal. Al vincular España derechos humanos a una condición administrativa se legalidad se vulneran derechos fundamentales. Se debería distinguir entre derechos humanos con otros derechos, aquéllos no deben quedar subordinados a la situación administrativa. Ciertamente, existen otros derechos cuya concesión o no depende de lo que las Administraciones consideren oportuno, la administración es libre para conceder o denegar a los inmigrantes. En todo caso, éstos sobre todo los irregulares en muchas ocasiones no pueden acceder a éstos, o para lograrlos deben superar excesivos obstáculos.

Título: "CRUZ ROJA Y LA ACOGIDA DE LOS REFUGIADOS EN LEÓN"

Comunicante: Dña. Marta Cuesta Martínez. Coordinadora Provincial de Cruz Roja León (CRE)

El Programa de acogida e integración de personas solicitantes y beneficiarias de protección internacional se trata de un sistema mixto (administración + entidades) coordinado por la Secretaría de Estado de Migraciones del Ministerio de Trabajo Migraciones y Seguridad Social.

\section{La red estatal de acogida engloba:}

- Los Centros de Migraciones dependientes de la Dirección General de Migraciones (DGM) que incluyen: Los CAR (Alcobendas, Vallecas, Mislata y Sevilla), destinados a solicitantes y beneficiarios de protección internacional, solicitantes y beneficiarios del estatuto de apátrida en España. Los CETI de Ceuta y Melilla, destinados tanto al colectivo citado anteriormente como a inmigrantes que acceden de forma irregular a estas ciudades autónomas.

- Otros dispositivos de acogida, subvencionados por el Ministerio de Trabajo Migraciones y Seguridad Social (MTM) y gestionados por las Entidades colaboradoras, destinados al mismo colectivo.

Los programas y recursos complementarios necesarios para favorecer medidas de integración que faciliten a los beneficiarios desenvolverse en el nuevo entorno y acceder a puestos de empleo e integrarse en la sociedad de acogida, Durante 30 años las únicas entidades colaboradoras de la red estatal de acogida fueron: CRUZ ROJA/ACCEM/ CEAR.

Sin embargo, dado el incremento en el número de solicitantes de protección internacional $\mathrm{y}$, sobre todo, los compromisos de reasentamiento y reubicación adquiridos por el gobierno español se han incorporado como entidades 
colaboradoras: CEPAIM/ DIANOVA/RED ACOGE/LA MERCED/APIPACAM/PROVIVIENDA/ FUNDACION LA MERCED MIGRACIONES / (...) La red estatal (CAR administración + entidades) cuenta actualmente con una capacidad de 5.359* plazas, de las que Cruz Roja gestiona un 48\% (2.581).

\section{Objetivo general}

Acogida e Integración de personas solicitantes y beneficiarias de Protección Internacional con el objetivo último de conseguir su autonomía e integración en la sociedad española.

\section{Fases del programa}

\begin{tabular}{|c|c|c|c|}
\hline $\begin{array}{c}\text { FASE DE ACOGIDA Y } \\
\text { DIAGNÓSTICO }\end{array}$ & PRIMERA FASE & SEGUNDA FASE & TERCERA FASE \\
\hline $1^{\text {a }}$ Acogida & $\begin{array}{c}\text { Acogida temporal en } \\
\text { centro }\end{array}$ & Integración & Autonomía \\
\hline
\end{tabular}

Teniendo en cuenta que nuestra intervención busca la integración de las personas solicitantes de asilo en la sociedad de acogida, se cuenta con una amplia red de personal técnico y voluntario para facilitar esta tarea.

Estas fases tienen una duración media de 18 a 24 meses.

\section{Servicios Transversales}
a) Aprendizaje del castellano
b) Ayudas económicas
c) Atención psicológica
d) Empleo
e) Asistencia legal y jurídica
f) Interpretación y traducción

DATOS PARTICIPANTES DEL PROGRAMA. CRUZ ROJA LEÓN: Situación actual

\begin{tabular}{|c|c|c|c|}
\hline $\begin{array}{c}\text { Fase I: } \\
\text { ACOGIDA TEMPORAL }\end{array}$ & $\begin{array}{c}\text { Fase II: } \\
\text { INTEGRACIÓN }\end{array}$ & $\begin{array}{c}\text { Fase III: } \\
\text { AUTONOMÍA }\end{array}$ & $\begin{array}{c}\text { TOTAL BENEFICIARIOS } \\
\text { PROGRAMA ASILO }\end{array}$ \\
\hline Plazas & N $^{0}$ Beneficiarios & No Beneficiarios & 63 \\
\hline 33 & 14 & 26 & \\
\hline
\end{tabular}

Resumen Datos Programa de Acogida e Integración de personas solicitantes y beneficiarias de Protección Internacional. León 2016-2018.

\begin{tabular}{|c|c|c|c|c|c|}
\hline HOMBRES & MUJERES & ADULTOS & MENORES & U.F. & INDEPENDIENTES \\
\hline 66 & 84 & 80 & 70 & 135 & 15 \\
\hline $44 \%$ & $56 \%$ & $53 \%$ & $47 \%$ & $90 \%$ & $10 \%$ \\
\hline
\end{tabular}




\begin{tabular}{|l|c|c|}
\hline \multicolumn{3}{|c|}{ SITUACIÓN LEGAL ADMINISTRATIVA } \\
\hline Solicitantes & 111 & $74,00 \%$ \\
Beneficiarios & 31 & $20,67 \%$ \\
Solicitantes inadmitidos & 1 & $0,67 \%$ \\
Inmigrantes irregulares & 6 & $4,00 \%$ \\
En proceso de solicitud & 1 & $0,67 \%$ \\
\hline Total & 150 & $100 \%$ \\
\hline
\end{tabular}

\begin{tabular}{|l|r|r|}
\hline \multicolumn{3}{|c|}{ NACIONALIDADES } \\
\hline Afganistan & 7 & $4,67 \%$ \\
Brasil & 1 & $0,67 \%$ \\
Colombia & 16 & $10,67 \%$ \\
Ecuador & 1 & $0,67 \%$ \\
El Salvador & 8 & $5,33 \%$ \\
España & 1 & $0,67 \%$ \\
Georgia & 3 & $2,00 \%$ \\
Nicaragua & 4 & $2,67 \%$ \\
Pakistan & 3 & $2,00 \%$ \\
Palestina & 6 & $4,00 \%$ \\
Rusia & 4 & $2,67 \%$ \\
Siria & 38 & $25,33 \%$ \\
Somalia & 7 & $4,67 \%$ \\
Ucrania & 11 & $7,33 \%$ \\
Venezuela & 40 & $26,67 \%$ \\
\hline Total & 150 & $100 \%$ \\
\hline
\end{tabular}

Título: "ACCEM Y LA ASISTENCIA JURÍDICA A LOS REFUGIADOS EN LEÓN" Comunicante: Dña. Natalia Cañiz García. Abogada del Colegio de Abogados de Madrid. Letrada del Servicio Jurídico de Accem en León

El asilo consiste -en líneas generales- en otorgar protección frente a la persecución, persecución entendida como una violación grave y sistemática de los derechos humanos: casi siempre lo asociamos personas que huyen de un país en guerra o a una persecución por motivos políticos, pero también existe una persecución por motivos de género: mutilación genital femenina, matrimonios forzados o de edad temprana, homicidios por motivos de honor, violencia doméstica, ataques con ácido, violación y otras formas de agresión sexual, esterilización forzada, la persecución por manifestar opiniones feministas, por reivindicar sus derechos, por no acatar las normas y convenciones sociales y como no, la trata con fines de explotación sexual son algunas de las formas de persecución que siguen sufriendo mayoritariamente mujeres y niñas. 
Los datos que conocemos - a punta del iceberg- señalan que un porcentaje muy elevado de las mujeres que ejercen la prostitución y de las que son víctimas de trata son mujeres extranjeras y muchas de ellas también están en situación irregular.

Es importante aclarar que no todas las extranjeras víctimas de trata son potenciales refugiadas, lo relevante para que se conceda asilo es determinar si existe un riesgo para esa persona en caso de retorno a su país:

- de volver a ser tratada

- de sufrir represalias x parte de la red/tratante

- o incluso de estigmatización social, ostracismo, discriminación o castigo por parte de la familia o comunidad

El procedimiento de solicitud de protección internacional no es incompatible con la solicitud por la vía de extranjería de un permiso de residencia como víctima de trata: ambas formas de protección no son excluyentes, sino complementarias (así lo recoge expresamente el RELOEX (art. 144.8 y art. 148.1 RELOEX. El contenido de este precepto no afectará al derecho que asiste al extranjero de solicitar y disfrutar de protección internacional). Hay que decir también que la posibilidad de obtener un permiso de residencia como víctima de trata por la vía de extranjería es un entramado legal especialmente complejo para las mujeres extranjeras, máxime cuando se encuentran indocumentadas.

Por tanto, parte de nuestra labor consiste en analizar si la posible víctima de trata reúne también un perfil que haga viable la solicitud de protección internacional. ¿Qué perfiles son esos?

- Puede haber sido una mujer sometida a trata en su país, que escape de la red y venga a España en busca de protección.

- Puede que haya sido captada por la red en su país, se la traslada fuera de él y sometida a trata fuera de su país de origen, escapa y busca protección en el Estado donde se encuentra.

- O incluso puede que nunca haya sido tratada pero teme serlo y huye a otro país venga a España en busca de protección.

Existe una aplicación muy restrictiva del derecho de asilo a las víctimas de trata: desde finales de 2016 se ha concedido protección internacional a 19 mujeres víctimas de trata, junto a 4 menores a su cargo (recalcar que son cifras no oficiales, la Oficina de Asilo no publica datos desglosados al respecto por lo que no se puede garantizar la precisión de las mismas, son datos internos que manejamos las ONGs).

El Protocolo marco de protección de las víctimas de trata de seres humanos, adoptado mediante acuerdo de 28 de octubre de 2011 por los Ministerios de Justicia, del Interior, de Empleo y Seguridad Social y de Sanidad, Servicios Sociales e Igualdad, la Fiscalía General del Estado y el Consejo del Poder Judicial, establece que "cuando en la instrucción de un expediente de solicitud de protección internacional se aprecien indicios de que la persona solicitante pudiera ser victima de trata de seres humanos, la Oficina de Asilo y Refugio lo pondrá en conocimiento de la Sección de Asilo de la 
Comisaría General de Extranjería y Fronteras a fin de que esta lo comunique a la unidad policial competente para su identificación, por si pudiera ser de aplicación lo establecido en el artículo 59 bis de la Ley Orgánica 4/2000, sobre derechos y libertades de los extranjeros en España y su integración social".

Por tanto, cuando la Oficina de Asilo advierte indicios de un posible caso de trata deriva a la Policía para la activación del Protocolo de protección a las víctimas y que continúe el caso por la vía de extranjería (art. 59 bis LOEX), denegando en la mayoría de los casos el asilo al entender que no encaja jurídicamente dentro de esta figura. A su vez, la Oficina de Asilo y Refugio lo pone en conocimiento del Ministerio de Empleo y Seguridad Social, encargado de la acogida integral e integración de los solicitantes de protección internacional, refugiados y apátridas para la búsqueda de un recurso de acogida adecuado, en caso de que la solicitud haya sido admitida a trámite.

La respuesta de los tribunales españoles tampoco ha sido favorable, la mayor parte de las sentencias del Tribunal Supremo son desestimatorias.

¿Cuáles suelen ser las razones de denegación?

- Se argumenta por parte de la Administración que se trata de casos de delincuencia común, que no encajan dentro de los motivos de persecución, restringido a "supuestos especialmente graves". Hay informes de instrucción de la OAR en lo que el único argumento de denegación es que ya existe la vía del art. 59 bis de la LOEX.

- Cuestiones relacionadas con la credibilidad del relato, al considerar que no está documentado, es vago, impreciso o contradictorio. Precisamente que el relato sea inverosímil es uno de los indicadores que pueden hacernos pensar que esa mujer está siendo tratada. Muchas veces siguiendo las indicaciones de la red mienten sobre su nacionalidad para evitar una posible expulsión, o traen historias aprendidas, estereotipadas. Por ello es tan importante que se realice un buen estudio del caso por parte de la OAR y que se lleve a cabo una segunda entrevista -o incluso una segunda solicitud- cuando la mujer se encuentre en condiciones de seguridad y confianza para poder narrar la persecución sufrida.

- No hay que perder de vista que estas mujeres realizan la entrevista inicial ante funcionarios de la Policía o de la propia OAR, tienen miedo de exponer su verdadera situación, a veces lo cual les perjudica enormemente ya que hace que sus alegaciones resulten inverosímiles y con ello muchas veces sean inadmitidas a trámite o denegadas por resultar incoherentes o incongruentes.

- Peculiaridad de este tipo de solicitudes: estas mujeres no son perseguidas por las autoridades de su país, sino por el tratante o la red de trata (agente de persecución no estatal), por lo que en estos casos hay que demostrar la falta de voluntad o la incapacidad su país para ofrecerles protección.

Hay que decir también que las autoridades son conscientes de que la mayoría de las mujeres de África subsahariana que están llegando a Ceuta y Melilla han sufrido trata, violencia sexual u otras formas de violencia de género y tienen miedo del supuesto efecto llamada, pero hay muy pocos traslados a la Península por el temor al efecto llamada. 
Es preocupante la exclusión de los ciudadanos/as comunitarios del derecho a solicitar protección internacional: muchas mujeres víctima de trata con fines de explotación sexual provienen de Rumanía.

Las víctimas de trata tienen la consideración en la ley de asilo de solicitantes en situación de especial vulnerabilidad, y prevé que en estos casos se adopten las medidas necesarias para dar un tratamiento diferenciado - cuando sea preciso- a sus solicitudes de protección internacional. Necesitan gozar de un apoyo adecuado: social, jurídico, unas condiciones de acogida particulares (vivienda, soporte social y sanitario adaptado a sus necesidades) que creen un clima de confianza. Sin embargo en la práctica no existe en nuestro país un mecanismo para evaluar si la persona solicitante tiene necesidad de unas condiciones procedimentales o de acogida especiales, como establecen las Directivas Comunitarias, en concreto, los arts. 21 y 22 de la Directiva 2013/33/UE, de 26 de junio de 2013, que dispone las normas de acogida de solicitantes de protección internacional y el art. 24 de la Directiva 2013/32/UE del Parlamento Europeo y del Consejo de 26 de junio de 2013, sobre procedimientos comunes para la concesión o la retirada de la protección internacional.

El Defensor del Pueblo reclama "la necesidad que existe de un procedimiento específico para la derivación de víctimas de trata a protección internacional es muy evidente. El Protocolo marco de protección de las víctimas de trata de seres humanos establece pautas de actuación que son insuficientes. Sin embargo, hasta el momento, la Administración no ha estimado necesario el establecimiento de un protocolo específico cuando concurren ambos procedimientos, y lo habitual es que, si existen indicios de trata, se aplique el procedimiento regulado en el régimen de extranjería".

España otorgó por primera vez el asilo a una víctima de trata en el año 2013: una joven nigeriana que había llegado a nuestras costas en 2010 a bordo de una patera. Esta chica había sido captada por la red de trata en su pueblo, con un familiar como intermediario, la red organizó el viaje para ella y para otras mujeres, un viaje que duró dos años, desde Nigeria hasta llegar a España, atravesando varios países africanos, y durante el cual fue obligada a prostituirse, sufrió múltiples vejaciones, agresiones físicas y sexuales, se quedó embarazada en varias ocasiones y en dos de ellas la obligaron a abortar con medios muy peligrosos.

Luego la metieron en una patera con otras mujeres y varios niños. Llegó a España, en 2010, embarazada.

Al poco de llegar la red la localizó y le exigió que devolviera la deuda de 20.000 euros que había contraído, para lo que sería llevada a un lugar donde debería prostituirse hasta pagar ese dinero. Ella entonces reuniendo valor decidió enfrentarse a la red, negarse a pagar esa deuda, y puesto que no podía regresar a Nigeria porque la tenían perfectamente localizada decidió solicitar protección internacional, y colaborar con las autoridades nacionales para desmantelar la red. Muchas de las mujeres que llegaron con ella desaparecieron porque la presión que sufren de las redes es infinita.

Hay que decir que en este tiempo la red la siguió buscando y contactando, obligándola a mudarse en repetidas ocasiones y a pasar por diversos centros de acogida, tuvo apoyo 
psicológico, ayuda con su hija pequeña y apoyo formativo y de búsqueda de empleo, en definitiva, un tratamiento integral para lograr una vida normalizada en España.

Este caso es un ejemplo muy representativo.

El trayecto migratorio de las mujeres y niñas subsaharianas está profundamente marcado por la violencia: física y sexual: que otros usen sus cuerpos se convierte en un sacrificio que asumen para el triunfo del proyecto migratorio. La trata se convierte en muchos casos en un peaje necesario, en la única manera de alcanzar Europa.

También la violencia reproductiva en forma de embarazos y abortos forzados: las redes saben que una mujer embarazada es más difícil deportar. Y también es frecuente que las redes se apropien de estos bebés como una forma de presión.

Para más información:

CEAR.: Identificación de las necesidades especiales de solicitantes de asilo víctimas de trata y respuesta a las mismas. Proyecto Tracks.

Defensor del Pueblo (2016): El asilo en España. La protección internacional y los recursos del sistema de acogida. Madrid.

Título: "MUJERES INMIGRANTES Y VIOLENCIA DE GÉNERO EN LEÓN" Comunicante: Dña. $\mathbf{M}^{\mathrm{a}}$. Cristina Prieto Puente. Directora del Centro de Día para Mujeres Inmigrantes en la Fundación Isadora Duncan

Para abordar la violencia que sufren las mujeres inmigrantes se requiere una visión multidisciplinar y tener en cuenta la complejidad de la violencia de género, unido a la complejidad de la inmigración.

Las mujeres inmigrantes son un colectivo especialmente vulnerable, ya que además de sufrir las desigualdades por ser mujer, sufren las desigualdades por ser inmigrante, lo que hace que estén más expuestas a la violencia de género, la trata de personas, especialmente con fines de explotación sexual, mutilación genital femenina y matrimonios forzosos.

Los factores a tener en cuenta y que les hacen especialmente vulnerables son: duelo migratorio, choque cultural y lingüístico, carencia de redes sociales naturales en las que poder apoyarse, fuerte dependencia respecto de su pareja, familia, la percepción de las instituciones públicas más como una amenaza que como fuente de protección y miedo a no ser creída o a que la denuncia de violencia de género pueda afectar al proceso de regularización.

Desde la Fundación contamos con dos programas, en los cuales trabajamos con mujeres inmigrantes víctimas de violencia:

Casa de Acogida para mujeres víctimas de violencia, encuadra dentro de la Red de Asistencia para Mujeres Víctimas de Violencia de Género, cuya dependencia 
es de la Junta de Castilla y León y se desarrolla en colaboración con Diputación y Ayuntamiento.

Esta red articula y coordina todos los recursos de la Comunidad para las víctimas de violencia, desde los servicios básicos hasta los especializados como es nuestra Casa de Acogida. Por lo tanto somos un recurso especializado para mujeres víctimas de violencia y para personas dependientes de éstas, que han denunciado o que tengan un certificado de la trabajadora social de que lo son, independientemente de su nacionalidad.

El trabajo con las mujeres acogidas es muy duro y requiere de mucho esfuerzo por parte de ellas, no solo por todo lo que conlleva romper el círculo de la violencia (denunciar a la persona de la que dependen emocionalmente y/o económicamente), cambiar toda su vida y entorno y enfrentarse con una nueva situación.

Centro de Día para Mujeres Inmigrantes, en el que trabajamos dos vertientes por una parte la atención integral a las mujeres inmigrantes, a través de los Servicios de Asesoramiento Social-laboral, jurídico y psicológico de cara a cubrir las demandas individuales y los talleres y clases de español para la adquisición de conocimientos para desenvolverse en nuestra sociedad y el acceso igualitario a los servicios públicos.

Y por otra la prevención y la sensibilización sobre las violencias que sufren las mujeres inmigrantes (violencia de género, trata de personas, mutilación genital, matrimonios forzosos) a profesionales y población en general mediante la organización de cursos de sensibilización para profesionales sobre mutilación genital femenina y las Jornadas de Mujeres Inmigrantes que este año serán nuestras XI Jornadas de Mujeres Inmigrantes: Víctimas Invisibles.

La información y la formación son los instrumentos con los que podemos contar para luchar contra esta lacra, sin olvidar lógicamente la coordinación entre los servicios especializados. Y por supuesto la concienciación social.

Tercera Mesa Redonda: "ENTRADA, RESIDENCIA, ACCESO AL MERCADO LABORAL E INTEGRACIÓN DE LOS MIGRANTES CON REFERENCIA A LAS VÍCTIMAS DE TRATA Y VIOLENCIA DE GÉNERO EN LEÓN: ACTUACIÓN DE ACTUACIÓN DE LA ADMINISTRACIÓN PÚBLICA"

Moderadora: Dra. Aurelia Álvarez Rodríguez. Profesora Titular, acreditada Catedrática, de Derecho Internacional Privado (ULE)

El objetivo de esta mesa redonda es brindar a los asistentes de una perspectiva institucional de la población migrante y de sus familiares residentes en la Provincia de León

Título: "LOS SERVICIOS DEL AYUNTAMIENTO DE LEÓN PARA LA INSERCIÓN DE INMIGRANTES"

Comunicante: Dra. Purificación Muñoz Graña. Coordinadora de Inclusión Social. Ayuntamiento de León 
Ha sido a finales del siglo pasado cuando España, impulsada por el acelerado ritmo de crecimiento económico adoptado en parte gracias a su integración económica en Europa, pasa de ser una economía emisora de emigrantes a una receptora de inmigrantes.

En España, la inmigración ha crecido de manera tal que mientras que en 1999 ésta representaba aproximadamente el $1,60 \%$ de la población total, actualmente supone más del 10\%.

Según el Padrón Municipal de Habitantes del municipio de León, el aumento de la población extranjera en la capital leonesa entre 1996 y 2003 fue de un 302,75\%, si bien la afluencia masiva de las décadas de 1980 y 1990 por el efecto llamada del empleo en la minería del carbón, se ha atenuado en parte. Así, mientras que la provincia leonesa acogía en 1994 el 44\% de los inmigrantes de la Comunidad Autónoma, según datos relativos al año 2013 es de sólo el 15,33\%. A la afluencia actual de población inmigrante, en línea con el conjunto estatal, hay que unir el impacto demográfico inducido a través de la natalidad. En los últimos cinco años, los nacimientos de madre extranjera se han multiplicado por tres.

Datos Estadísticos:

- El número de personas extranjeras empadronadas en León es de 9.920.

- Un 50,07\% se corresponde a mujeres y un 49, 93\% a varones.

- El porcentaje de población extranjera respecto del total de la población en León supone un $7,70 \%$.

- Hay presencia de 137 países distintos en nuestra ciudad.

En el año 2016 fue cuando más descendió la población extranjera en nuestra ciudad, respecto de este año ha habido un incremento del 5,7\%, si haber alcanzado el número máximo de población extranjera que fue en el año 2012.

\begin{tabular}{|c|c|c|l|}
\hline $\begin{array}{l}\text { TOTAL EXTRANJEROS } \\
\text { EMPADRONADOS } \\
\text { (incluidos comunitarios y no } \\
\text { comunitarios) }\end{array}$ & MUJERES & VARONES & FECHA \\
\hline 9.920 & 4.967 & 4.953 & Octubre 2018 \\
\hline 9.628 & 4.796 & 4.832 & Diciembre 2017 \\
\hline 9.394 & 4.662 & 4.732 & Diciembre 2016 \\
\hline 10.480 & 5.231 & 5.249 & Septiembre 2015 \\
\hline 10.482 & 5.243 & 5.239 & Septiembre 2014 \\
\hline 11.196 & 5.592 & 5.604 & Septiembre 2013 \\
\hline 11.546 & 5.803 & 5.743 & Noviembre 2012 \\
\hline 11.028 & 5.567 & 5.461 & Octubre 2011 \\
\hline
\end{tabular}

Datos globales de población extranjera empadronada de octubre de 2011 a septiembre de 2018.

Fuente: Padrón Municipal del Ayuntamiento de León. Elaboración propia. 
Los colectivos más representativos en León son los siguientes:

\begin{tabular}{|c|c|c|c|c|c|c|c|}
\hline PAÍS & $\begin{array}{l}2018 \\
\text { (0ct.) }\end{array}$ & $\begin{array}{l}2017 \\
\text { (Dic.) }\end{array}$ & $\begin{array}{c}2016 \\
\text { (Sep.) }\end{array}$ & $\begin{array}{c}2015 \\
\text { (Sep.) }\end{array}$ & $\begin{array}{c}2014 \\
\text { (Sep.) }\end{array}$ & $\begin{array}{c}2013 \\
\text { (Sep.) }\end{array}$ & $\begin{array}{c}2012 \\
\text { (Nov.) }\end{array}$ \\
\hline Marruecos & 1.769 & 1.725 & 1.725 & 1.893 & 1.888 & 1.968 & 1.975 \\
\hline Rumania & 1.418 & 1.483 & 1.481 & 1.496 & 1.444 & 1.464 & 1.480 \\
\hline Colombia & 642 & 586 & 532 & 733 & 785 & 996 & 1.113 \\
\hline R. Dominicana & 536 & 522 & 539 & 567 & 661 & 793 & 919 \\
\hline China & 534 & 524 & 507 & 514 & 474 & 459 & 483 \\
\hline Bulgaria & 511 & 548 & 545 & 537 & 534 & 577 & 581 \\
\hline Brasil & 436 & 429 & 461 & 663 & 649 & 692 & 704 \\
\hline Venezuela & 344 & 253 & 158 & 186 & 187 & 208 & 209 \\
\hline Portugal & 333 & 333 & 340 & 323 & 312 & 325 & 324 \\
\hline Italia & 237 & 226 & 207 & & & & \\
\hline Ecuador & 180 & 181 & 184 & 280 & 290 & 347 & 370 \\
\hline México & 161 & 159 & 157 & 192 & 195 & 183 & 197 \\
\hline Senegal & 153 & 148 & 149 & 180 & 185 & 194 & 194 \\
\hline Estados Unidos & 148 & 148 & 164 & & & & \\
\hline Perú & 127 & 106 & 88 & 112 & 121 & 159 & 171 \\
\hline Pakistán & 126 & 127 & 122 & 142 & 145 & 149 & 132 \\
\hline Argelia & 126 & 120 & 126 & 157 & 165 & 178 & 192 \\
\hline Francia & 119 & 123 & 119 & & & & \\
\hline Reino Unido & 119 & 121 & 112 & & & & \\
\hline Cuba & 117 & 106 & 91 & 98 & 97 & 114 & 131 \\
\hline Ucrania & 114 & 107 & 106 & & & & \\
\hline Paraguay & 96 & 85 & 89 & & & & \\
\hline Siria & 94 & 76 & 59 & & & & \\
\hline Argentina & 91 & 87 & 92 & 166 & 164 & 184 & 190 \\
\hline Rusia & 81 & 90 & 89 & 121 & 126 & 131 & 125 \\
\hline Nigeria & 49 & 49 & 47 & & & & \\
\hline Japón & 49 & 61 & 77 & & & & \\
\hline
\end{tabular}

Fuente: Padrón Municipal del Ayuntamiento de León. Elaboración propia.

En León la realidad no es ajena a esta circunstancia, pues hay 9900 personas extranjeras, población que ha sido minorada desde 2012. En un municipio donde las personas mayores de 65 años suponen más del $27 \%$ de la población total y que ha perdido casi 30.000 empadronados desde los años 90, la llegada de personas extranjeras ha supuesto el "rejuvenecimiento" de dicha población y una gran oportunidad en enriquecimiento para la ciudadanía leonesa.

Una de las medidas de inclusión e integración en la capital leonesa es la concesión de la renta garantizada por parte de la Junta de Castilla y León. Prestación que un 20\% de población percibe, en efecto, hay más de 1000 unidades familiares que la perciben. El Ayuntamiento y su papel, en concreto de las CEAS, es de realización de los informes de valoración, y de seguimiento para buscar la inclusión. Pero hay que precisar que de este porcentaje solo un $20 \%$ son unidades familiares de personas extranjeras, porque en la opinión publica crece la idea de que los inmigrantes acceden 
a toda las "ayudas públicas" y hay que explicar debidamente este hecho, actualmente las personas extranjeras ocupan la parte más baja de la escala social de aquí su acceso a los recursos públicos, siempre para los que tengan permiso de residencia en España. Cabe destacar la creación del Consejo Municipal de Inmigración en el año 2005, centro reconocido por la Castilla y León como centro integral de inmigración, con la obligación de prestar formación, e información sobre la inmigración en la ciudad de León. Destacando el asesoramiento jurídico que presta. Una de las principales dificultades a las que tienen que enfrentarse las personas inmigrantes en la sociedad de acogida es el desconocimiento del entorno y la cultura del país, de cuáles son sus derechos y qué recursos existen en el municipio. Además se facilita el acceso a los procesos de nacionalización de los extranjeros, mediante la formación en el idioma español y los contenidos de las pruebas de acceso.

Por ello desde el CEMAI, se informa sobre los derechos y obligaciones que asisten a las personas inmigrantes, se hacen los informes de arraigo, se desarrollan proyectos en materia de integración, especialmente en el ámbito educativo.

\section{Título: "SITUACIONES DE RESIDENCIA Y TRABAJO DE LOS EXTRANJEROS EN LEÓN"}

Comunicante: D. Álvaro Prieto Lorente. Jefe de Sección. Oficina de Extranjeros en León

A) Normativa aplicable:

- Ley 4/2000 de 11 de Enero, sobre derechos y libertades de los extranjeros en España y su integración social.

- Real Decreto 557/2011 de 20 de Abril.

- Ciudadanos de la UE y sus familiares: RD 240/2007 de 16 de Febrero.

- Dirección oficina de extranjeros de León: Avda. de Asturias nº4. 24008. León.

B) Situaciones de residencia y trabajo:

1) Régimen comunitario: Los ciudadanos de un Estado miembro de la Unión Europea, de otro Estado parte en el Acuerdo sobre el Espacio Económico Europeo o de Suiza pueden darse de alta libremente en la TGSS como trabajadores por cuenta ajena o propia. Si van a residir en España por un período superior a tres meses están obligados a solicitar su inscripción en el Registro Central de Extranjeros para obtener su certificado de ciudadano de la UE, trámite realizado en la Comisaría Provincial de Policía. Para ello habrán de presentar su alta en la SS como trabajador, o acreditar que disponen de medios económicos suficientes o que son estudiantes.

- Los familiares extracomunitarios de un ciudadano de la UE: Con carácter general pueden darse de alta libremente en la TGSS como trabajadores por cuenta ajena o propia, mientras se encuentren en edad laboral.

2) Régimen extracomunitario: Los ciudadanos de un Estado no miembro de la Unión Europea para poder trabajar en España habrán de obtener el correspondiente permiso de trabajo y residencia, que podrá ser por cuenta ajena o propia: 
a) Por cuenta ajena: Hay que tener en cuenta que los trabajadores extranjeros extracomunitarios, con carácter general y debido en gran parte a la crisis económica que sufrimos aún, salvo en los casos de Perú y Chile en que existe un convenio específico, sólo pueden ocupar los puestos de trabajo contenidos en la Lista de Ocupaciones de Difícil Cobertura, que publica el INEM trimestralmente por provincias. En el caso de León, como en la mayoría de provincias, dichos puestos de trabajo consisten básicamente en los de deportista profesional y entrenador deportivo y varios puestos específicos correspondientes al sector naval. En el caso de que el puesto solicitado no se encuentre en dicha lista, el empresario (persona que ha de realizar los trámites para la obtención del permiso, ya que el ciudadano extranjero ha de encontrarse durante dicha tramitación en su país de origen) deberá solicitar a la Oficina del INEM respectiva un certificado de insuficiencia de candidatos idóneos y disponibles, tras presentar la oferta de trabajo en dicha Oficina y no hallar ningún trabajador disponible.

b) Por cuenta propia: Sujeto legitimado para presentar la solicitud es el ciudadano extranjero, personalmente en la misión diplomática u oficina consular española correspondiente a su lugar de residencia. En el caso de concesión, el trabajador dispone de un mes desde la notificación para solicitar personalmente el visado. Una vez recogido dicho visado, el trabajador deberá entrar en territorio español en su plazo de vigencia, que será de tres meses con carácter general. A partir de su entrada en España, el trabajador dispone de tres meses para que se efectúe su afiliación, alta y posterior cotización en los términos establecidos por la normativa de Seguridad Social. En el plazo de un mes desde que el trabajador se haya dado de alta en la Seguridad Social, deberá solicitar, personalmente, la Tarjeta de Identidad de Extranjeros en la Comisaría de Policía de la provincia donde se haya tramitado la autorización.

Título: "LA SEGURIDAD SOCIAL DE LOS EXTRANJEROS EN SITUACIÓN IRREGULAR"

Comunicante: Dr. Roberto Fernández Fernández, Profesor Titular de Derecho laboral y de la SS (ULE)

La prestación de servicios del inmigrante no autorizado para trabajar en España tiene, al igual que ocurre con otros derechos laborales fundamentalmente a partir de la Ley Orgánica 4/2000, de 11 de enero, de Extranjería, efectos en materia de Seguridad Social, pues así lo ha decidido el legislador. En efecto, el artículo 36.5 LOEx prevé que la carencia de la autorización de residencia y trabajo, sin perjuicio de las responsabilidades del empresario a que pudiera dar lugar, incluidas las de Seguridad Social, no será obstáculo para la obtención de determinadas prestaciones.

Eso sí, inmediatamente el precepto viene a establecer que el trabajador carente de autorización de residencia y trabajo no podrá obtener prestaciones por desempleo, y salvo en los casos legalmente previstos, el reconocimiento de una prestación no modificará la situación administrativa del extranjero. 
Tal situación significa que el extranjero en situación irregular va a tener derecho a acceder a una serie de prestaciones en el sistema español de Seguridad Social, pero dicha protección no es absoluta sino que está limitada a ciertas situaciones de necesidad, con independencia de la posible responsabilidad que pueda asumir el empresario incumplidor en relación con las mismas.

Así, según la jurisprudencia, el trabajador extranjero que presente servicios retribuidos por cuenta ajena aún sin contar con los preceptivos permisos legales, no puede verse privado de la protección inherente al contrato de trabajo y que responde a los deberes impuestos por los Tratados y Convenios internacionales ratificados por España, de manera que el irregular se encontraría incluido "en el campo de protección de la Seguridad Social, a los efectos de la contingencia de accidente de trabajo, por tratarse de extranjero hispanoamericano, cuyo país de origen ratificó el Convenio número 19 de la OIT, pues [...] obliga a conceder a los nacionales del otro Estado, que fueren víctimas de accidentes de trabajo ocurridos en el territorio de aquel, el mismo trato que otorgue a sus nacionales en materia de indemnización por accidentes de trabajo" [STS 7 octubre 2003 (Rec. 2153/2002)].

Conforme se ha dicho, el legislador excluye el acceso a la prestación por desempleo, habida cuenta de que el extranjero en situación irregular no puede acreditar el cumplimiento de cuantos requisitos establece la norma a fin de lucrar la prestación por desempleo, habida cuenta de que no va a poder estar disponible para buscar activamente empleo y acceder a una colocación adecuada (SSTS 18 marzo y 12 noviembre 2008 (Rec. 800/2007 y 3177/2007)].

Eso sí, algún pronunciamiento ha imputado una responsabilidad directa del empresario en forma de indemnización de daños y perjuicios y sin garantía a cargo de la Seguridad Social [STSJ País Vasco 22 diciembre 2015 (Rec. 2325/2015)]; en cambio, otros pronunciamientos niegan la posibilidad de nacimiento de dicha responsabilidad de carácter indemnizatorio [STSJ Cataluña 14 diciembre 2015 (Rec. 3972/2015)].

Como colofón, el Decano de la Facultad de Derecho Dr. Juan José Fernández Domínguez procedió al acto de clausura, en la que se puso de manifiesto que actos como el VI Seminario, revitalizan la Universidad al otorgar un espacio para la divulgación jurídica y el debate.

\section{CONCLUSIONES}

Como corolario lógico, podemos afirmar que el VI Seminario sobre relaciones internacionales ha cumplido con su fin, crear un lugar de encuentro donde se analizan temas relevantes, en concreto, las familias migrantes, las dificultades y obstáculos que tienen que superar los migrantes y los refugiados para poder integrarse en las sociedades de acogida con sus familiares, cónyuges, descendientes y ascendientes. Antes de finalizar debemos poner de manifiesto que todo ello no hubiese sido posible sin la labor realizada por todos los profesores e investigadores que forman parte del Grupo ULE de Innovación Docente "Inmigración, Nacionalidad e Interculturalidad" 
y del Grupo de Investigación Relativo a la Regulación de los Flujos Migratorios (INNAIN/GID-INI) junto con el Grupo de Investigación: Extranjería y Migración (UNED); así como del Programa de Doctorado: Protección jurídica y cohesión social (ULE) y al Master Universitario en Derechos Humanos (Uned). Asimismo, agradecer la colaboración de profesionales procedentes de diversas instituciones e investigadores y docentes tanto de la Universidad de Salamanca y de la Uned como de la Universidad de León, que han acudido sin dudar a este Jornada, compartiendo sus saberes y conocimientos.

En la organización y en la infraestructura nuestra gratitud no solo al Vicerrectorado de de Relaciones Institucionales y con la Sociedad (ULE) y al Ayuntamiento de León sino también a los siguientes Centros y Departamentos de la ULE: Facultad de Derecho, Facultad de Ciencias del Trabajo; Departamento de Derecho Privado y de la Empresa y Departamento de Derecho Público. Y, también hemos contado con la colaboración del Ilustre Colegio de Abogados de León, Cruz Roja Española en Castilla y León, Amnistía Internacional en Castilla y León, Caritas Diocesana León, la Fundación Sierra Pambley y la Fundación Isadora Duncan.

A nivel institucional, el Ministerio del Interior y el Ministerio de Trabajo, Migraciones y Seguridad Social. De este último ministerio se desplazaron hasta León, dos Directores Generales de la Secretaria de Estado para las Migraciones. Los asistentes han podido escuchar las líneas políticas que se están diseñando a nivel estatal en materia migratoria y de protección internacional. Por ello, nuestra muestra especial de mención de gratitud a D. José Alarcón Hernández y a Dña. Estrella Rodríguez Pardo, responsables de la Dirección General de las Migraciones y de la Dirección General de Integración y Atención humanitaria, respectivamente.

En todo caso, cabe reseñar que todas las actividades descritas pueden consultarse en los materiales audiovisuales editados por la ULE: I Seminario sobre relaciones jurídicas internacionales: familia e interculturalidad (https://videos.unileon.es/es/ serial/95.html); II Seminario sobre relaciones jurídicas internacionales: Inmigración Educación e Interculturalidad (https:/videos.unileon.es/es/serial/132.html); III Seminario sobre relaciones jurídicas internacionales: El reto de la integración de los inmigrantes y su repercusión en la UE (https://videos.unileon.es/es/serial/154.html); IV Seminario sobre relaciones jurídicas internacionales: Avances y retrocesos en la política migratoria de la Unión Europea (https://videos.unileon.es/es/serial/189.html); Curso de Verano: Status jurídico de los extranjeros en la UE y su implicación en las políticas de integración, ¿realidad o ficción? (https://videos.unileon.es/es/serial/187.html); V Seminario sobre relaciones jurídicas internacionales: infancia, MENAS, resolución de conflictos familiares y culturales (https://videos.unileon.es/es/serial/214.html); y VI Seminario sobre relaciones jurídicas internacionales: nuevos retos para la acogida e integración de las familias migrantes (https://videos.unileon.es/es/serial/234.html). 